\title{
LA JUSTICIA DE PAZ EN COLOMBIA: DISCURSO Y PRAXIS
}

\author{
WILHELM LONDOÑO DÍAZ
}

The effort to establish peace justice in Colombia has been defended by arguing that this alternative in conflict resolution allows greater efficiency in the administration of justice, and simultaneously allows the inclusion of cultural features of the communities where it is adopted. This article presents a critical examination of peace justice in the interpretative context of discursive analysis, with the objective of going beyond the traditional defenses to this concept presented by the Colombian government, non- governmental organizations and academic institutions.

\section{Introducción}

Desde hace más de una década se viene hablando en Colombia, dentro y fuera de los escenarios académicos, de los medios alternativos de solución de conflictos -MASC-, de la justicia comunitaria, de los jueces de paz, del pluralismo jurídico y de los usos alternativos del derecho y del derecho alternativo (cf. Carvajal, 1999; Corporación Región y Red de Justicia Comunitaria, 2000; Gordillo y Arias, 2002; Corporación Excelencia a la Justicia y Contraloría General de la República, 2003). Vistas las cosas desde una postura crítica, todo este abigarrado andamiaje conceptual se presenta como una suerte de eclosión de lo jurídico que ha sido presentado por varios académicos como los resultados propios y coherentes de la denominada "crisis de la administración de justicia" (cf. Santos, 1991). La crisis a la que se alude ha sido presentada en varias reflexiones en una doble dimensión. Por un lado, como el fracaso del paradigma contractualista que fundó el Estado moderno, y de otro, como las adaptaciones propias del sistema capitalista una vez eliminado el modelo del Estado de Bienestar (cf. Ardila, 2000a, 2002). 
A pesar de que se ha tenido en cuenta que los procesos de comunitarización de la justicia en Colombia están relacionados con las nuevas lógicas del capitalismo transnacional y su incidencia en la transformación del Estado (cf. Ardila, 2000a), el caso es que desde el discurso de varias organizaciones no gubernamentales y de organizaciones gubernamentales se le ha prestado poca atención a este tipo de conexiones y en algunas ocasiones se las ha pasado por alto (e.g. Sanín, 2000).

La situación anteriormente descrita ha llevado a la construcción de una serie de apologías sobre la justicia de paz que se basan en las posibilidades lógicas que tienen los modelos teóricos que apelan a la diferenciación entre las estrategias de administración de justicia adjudicatorias y las consensuales (cf. Ardila 2000b). Según esta diferenciación, las ventajas propias de la administración de justicia consensual, la cual se supone está presente en todo tipo de organización social por fuera del Estado, radica en que en la resolución de una disputa nunca hay vencedores ni vencidos, caso contrario al de la justicia adjudicatoria propia del Estado, en la cual una parte siempre debe soportar el peso de la sanción negativa, lo que implica que la parte amonestada pueda mantener la tensión que dio origen al conflicto. Según este paradigma, la justicia de paz, como ejemplo de justicia consensual, tiene en consecuencia la posibilidad de disolver los conflictos responsables de las altas tasas de morbimortalidad en el país, ya que inhibe la continuidad de las tensiones y su marcha hacia la agresión física.

Aunque la diferenciación entre el modelo adjudicatorio y el consensual es útil y hasta deseable, el caso es que dicha distinción funciona discursivamente para apuntalar reformas al sistema jurídico que favorecen las políticas de Estado, del mercado, de la cooperación internacional y de la consultoría, y que a la final diezman las posibilidades de agenciamiento de los movimientos sociales. Es así como a nombre de los grupos sociales marginales se construye toda una infraestructura de la intervención que favorece a todos los poderes menos a los locales.

\section{Análisis discursivo}

La mayor contribución de la tradición racionalista francesa ha sido sin lugar a dudas el desplazamiento de la razón como plataforma de la producción cultural y el centramiento del poder como insumo básico en las elaboraciones humanas. Pero no el poder como lo suponía el marxismo, dotado de la cualidad de encubrir una realidad que se podía aprehender por la desideologización, 
sino como escenario de la producción misma de la realidad social. Esto fue sin lugar a dudas lo que entendió F. W. Nietzsche al examinar diversos discursos históricos: cada tiempo -cada cultura, agregaría yo- crea sus propios valores, sus propios marcos de representación, sus propias lógicas, y ese producto, la cultura como la denominamos en antropología, se ofrece a los individuos como una exterioridad que impone su propio peso en la experiencia vital. Pasando revista a un aforismo de este pensador alemán encontramos:

Estoy sentado aquí en actitud de espera, rodeado de viejas tablas rotas y otras nuevas a medio escribir. ¿Cuándo llegará mi hora? - La hora de mi ocaso y perdición; pues una última vez quiero encaminarme a los hombres (Nietzsche, [1881] 1993:11).

Como se ve, los valores representados en las tablas han sido rotos, como en el cristianismo, por la emergencia de la modernidad, o han aparecido nuevos como el de los modernismos, o hay unos nuevos por escribir como la propia voz de Nietzsche que hizo eco en la prosa de Michel Foucault. Es así como de la obra de este pensador francés aparece la obsesión por el discurso, que podríamos decir se relaciona de manera inmediata con los valores, yo diría con la cultura, con aquellos preceptos que nos permiten evaluar y configurar la realidad. Aunque Foucault nunca ofreció una definición concreta del discurso, sí mencionó algo de su funcionalidad, en sus palabras:

[...]supongo que en toda sociedad la producción del discurso está a la vez controlada, seleccionada y redistribuida por cierto número de procedimientos que tienen por función conjurar sus poderes y peligros, dominar el acontecimiento aleatorio y esquivar su pesada y temible materialidad (Foucault 1999a:14).

De esta manera, los valores, el discurso, la cultura, son producidos con el imperativo funcional de la institucionalidad que marca de manera concreta la frontera entre la identidad y la alteridad, entre lo normal y lo anormal, entro lo legal y lo ilegal. Así, la institucionalidad reduce el margen de creación en la producción cultural, limita la hermenéutica que le es inherente y la presenta como resultante de la aplicación de preceptos que están por fuera del alcance de cualquier individualidad.

No existe discurso, producción cultural más regulada y fetichizada que el derecho, diría que por antonomasia representa la instancia institucional y oficial del discurso. Lo importante de estas argumentaciones es que la justicia de paz existe, es producida, solo en el instante en que es pronunciada por el 
aparato institucional (e.g. la Constitución), y su voz sólo es posible leerla en la traducción que hace la oficialidad en el momento en que, en el marco de las macrorreformas estructurales que induce la neoliberalización, los gobiernos de los Estados Nación son llamados a producir una crisis en los sistemas jurídicos que ellos mismos solventarán.

\section{El discurso oficial de la justicia de paz}

La creación de la justicia de paz en Colombia como realidad social se dio con base en tres paradigmas interrelacionados, cada uno aportando su propia legitimidad con diferentes énfasis. En primer lugar el discurso de la autorregulación, por el cual se supone que la tesis contractual que fundamenta el Estado Nación debe ceder hacia el reconocimiento de que hay cosas que ese gran Leviatán está en incapacidad de manejar en medio de la cotidianidad de los ciudadanos. Por ello, a los ciudadanos no les basta con ceder la gobernabilidad de sí mismos a un tercero como lo suponía Hobbes, sino que además deben actuar como leviatanes en esos recodos donde ese gran dios mortal no puede acceder. El segundo gran paradigma que legitimó la existencia de la justicia de paz fue el de la multiculturalidad. Según este discurso resulta insultante que el Estado Nación intente imponer su propia lógica de resolución de disputas a otras tradiciones jurídicas que manejan sus conflictos de acuerdo con principios vernáculos funcionalmente más adecuados que los del Estado. Por último, el tercer paradigma con el cual se construyó la justicia de paz fue el de la descongestión de los despachos judiciales. Se supone que en el Estado colombiano los problemas de impunidad emergen porque los oficiales están ocupados en resolver pequeñas disputas que se pueden dejar a las comunidades organizadas según sus propios preceptos de lo justo. Pasemos revista a cada uno de estos argumentos.

\section{El discurso de la autorregulación}

El tema de la autorregulación ha sido de gran relevancia en los debates contemporáneos en torno de la justicia. La lógica interna de este discurso supone que en aras de la maximización del capital los Estados deben promover la racionalización del arsenal jurídico, ya que en un proceso ordinario el Estado debe invertir hasta un 170\% más que la cuantía en disputa (cf. Uprinmy, 2000: 59); en consecuencia, para los ciudadanos de las democracias desarrolladas resulta relevante minimizar gastos en lo jurídico para cualificar otros servicios como salud y educación. Esta política ha tenido gran acogida en países como Francia. $\mathrm{Al}$ respecto, la comentarista de este proceso Elian Botelho ha escrito: 
A pesar de estos obstáculos, el proceso de informalización de la justicia francesa constituye ejemplo privilegiado de este movimiento de creación de polos de regulación por el Estado y por la "sociedad civil", en sustitución del orden reglamentador establecido por la Revolución Francesa (Botelho 1993: 13).

Pero el tema de la autorregulación no se agota en los procesos de informalización de la justicia, o en la resolución no estatal de las disputas. Para el caso colombiano se ha hablado de que los jueces de paz pueden actuar como nodos en la desactivación de los desenlaces fatales de las disputas que acontecen en las grandes ciudades del país. Según Jaime Fajardo, político responsable en gran medida de la emisión del discurso de la justicia de paz:

Creemos que la crisis que nos asuela comienza por la inadecuada atención que se les presta a los problemas de policía, a las diferencias entre vecinos. Aunque jurisconsultos y criminalistas miren con desdén esas refriegas de barriada, la verdad es que de su descuido nace la decreciente fe en una convivencia organizada. De allí al "sálvate y defiéndete como puedas" con fuerza y argumentos propios hay un paso apenas a la violencia (Abello, citado por Fajardo, 1991b: 1).

La autorregulación puede verse entonces en dos contextos complementarios: como una estrategia para reducir la utilización del sistema jurídico estatal a través de la creación de formas alternativas de resolución de disputas, o de otra parte como instancias para la prevención de tensiones, en el caso colombiano, que terminan con muertes violentas. Sin embargo, estos dos polos de la autorregulación son impensables en todas las democracias actuales, como lo señala Eliane Botelho para el caso brasilero:

Si para la sociedad francesa se impone el desafío de crear fuera del Estado otros lugares de regulación autónoma, en el Brasil el movimiento que debe ser realizado tiene un sentido inverso, ya que [...] se busca ocupar-finalmente- los espacios públicos apropiados privadamente por determinados grupos que lograron penetrar en la máquina estatal. En otros términos, el desafío para la sociedad brasilera consiste no en crear espacios autónomos en la órbita de lo privado, sino en introducirse en la máquina estatal, formalizando y normatizando sus demandas e intereses (Botelho, 1993: 18).

Para los países periféricos como Colombia, en los cuales funcionan democracias muy problemáticas en medio de grandes márgenes de población 
en condiciones de pobreza extrema, es impensable no ejercer algún tipo de presión para ocupar de manera concreta lugares estratégicos dentro del Estado. A pesar de esto, el apoyo que se le ha dado a la informalización de la justicia en Colombia ha estado centrado en la formación de operadores judiciales como apéndices del sistema jurídico formal, de tal suerte que desde estos escenarios ha sido imposible la generación de un movimiento social que intente desplazar a los poderes privados que ostentan el poder de Estado.

\section{Política multicultural}

Una de las características centrales de la justicia de paz es su cercanía, en la Constitución, a la jurisdicción especial indígena, lo cual la convierte no tanto en una estrategia para la democratización de la justicia, sino en un dispositivo de política multicultural. Al respecto se puede leer en los debates constitucionales que precedieron el artículo 247:

No solamente se es violento con los briosos caballos, que pusieron en derrota a los chibchas, montados por los jinetes de Quesada, ni por las balas de los fusiles que han desalojado de sus tierras a los indígenas, también se es violento si se los juzga con leyes ajenas a sus tradiciones, que por lo mismo lastiman su autonomía (Fajardo 1991a:3).

Si bien es cierto que la aplicación del derecho positivo en comunidades indígenas es una expresión elocuente de colonialismo, en el debate constitucional la justicia de paz fue equiparada sin ninguna discusión de fondo a una forma local de justicia que por discriminación negativa no era ni indígena ni afrocolombiana, pero en todo caso algo con la suficiente coherencia cultural para imputarle un sistema de ideas que en derecho se llama "justo comunitario".

El argumento fue más allá y señaló que la necesidad de la justicia de paz radicaba en que en cada comunidad existía un derecho construido de acuerdo con las necesidades locales, lo que garantizaba su eficacia y ponía en entredicho la utilidad de un sistema de justicia positivo construido con otros propósitos. $\mathrm{Al}$ respecto se puede leer:

Existe una tradición jurídica propia caracterizada, en términos generales, por la ausencia de codificación. Un Derecho generado a partir de la especificidad en el que existe participación de los asociados tanto en su generación como en la aplicación. Estas formas propias no son 
heterónomas, ni implantadas. Por el contrario, este Derecho de carácter consuetudinario parte de las necesidades concretas y busca soluciones que se adecuen a la especificidad étnica (Fajardo, 1991a: 4).

\section{Descongestión de los despachos judiciales}

Más allá de pensarse como un dispositivo para la autorregulación, o como política multicultural, la justicia de paz ha sido entendida desde diversos ámbitos como una estrategia de apoyo al sistema jurídico formal. Según este argumento los jueces de paz junto con otro tipo de operadores, como los conciliadores en equidad, en derecho, los amigables componedores y demás, son constitutivos de la rama judicial por cuanto participan en la oferta de servicios jurídicos oficiales. Como lo ha señalado uno de los participantes en la implantación de la justicia de paz:

Conscientes de la crisis por que atravesaba -y atraviesa- la administración de justicia, se consagraron formas que correspondían al sustancial ánimo de ampliar la cobertura del servicio, reducir su morosidad, y como consecuencia de ello, recuperar la credibilidad del ciudadano en ella (Andrade, 1999: 14).

La descongestión de los despachos judiciales ha sido uno de los pilares fundamentales en la producción discursiva de la crisis del derecho. Se ha hablado de que el sistema formal de justicia ha colapsado por una excesiva demanda, y las respuestas a la crisis no se han dado atendiendo a los factores estructurales de la marginalidad, sino que por el contrario se han abordado abriendo mayores canales para la denuncia, la producción de actas ejecutivas, el fortalecimiento de la policía, todo esto con el paradigma de la seguridad y la convivencia. Dentro del eje de la descongestión de los despachos judiciales es donde ha hecho carrera un eufemismo propio de los consultores sociales que se ha denominado "acceso a la justicia". Cuando aparece la Ley 497 de 1999 que desarrolla el artículo constitucional 247 sobre la justicia de paz, se desplaza la argumentación de esta política como autorregulación o multiculturalismo hacia la justicia de paz como apéndice del Estado. En el marco de los debates de la ley se puede leer:

Uno de los problemas centrales de la administración de justicia es el relativo a la falta de acceso de los ciudadanos a este servicio público esencial. Con ello, el tradicional conflicto colombiano se ve favorecido por una situación de injusticia y, por tanto, por una crónica ausencia de solución de conflictos (Rengifo y Ocampo, 1997: 11). 
Esta estrategia de apertura a los servicios jurídicos ha encontrado eco en la emergencia de las famosas Casas de Justicia localizadas en las periferias de las grandes ciudades de Colombia. En el marco de estas instituciones que atienden conflictos urbanos, los indicadores de gestión han sido diseñados para cuantificar el número de usuarios, y el número que de ellos salen beneficiados a través de la producción de una acta que presta mérito ejecutivo. En consecuencia este discurso señala que hay más justicia en tanto haya más procesos que terminan en la movilización de las fuerzas represivas del Estado, como la fiscalía o la policía.

\section{Discurso de las organizaciones no gubernamentales sociales}

En el país han venido trabajando varias organizaciones no gubernamentales para la implementación de la justicia de paz, retóricamente, como un dispositivo de empoderamiento y emancipación, y en la praxis como política de apoyo al sistema formal de justicia. Todas las publicaciones que recogen el paradigma de estas organizaciones en relación con la justicia de paz han apelado a varios argumentos para su justificación, los cuales son derivaciones de los tres ejes reseñados arriba en el discurso oficial. Por ejemplo, se la ha considerado como una herencia histórica, como una forma alternativa de lo justo, como una estrategia para la construcción de ciudadanía, como una respuesta ineludible ante la crisis cuantitativa de la rama judicial y como posibilidad educativa.

La tesis de la justicia de paz como herencia histórica ha sido esgrimida en tono panegírico por varios autores y en diversos contextos. En una de las apologías de la justicia de paz se lee:

Quizá [...] García Márquez tiene razón cuando afirma que en estas latitudes el tiempo no se mueve ni hacia delante ni hacia atrás, sino en círculos, de tal manera que siempre estamos inventando el inicio. Pero tal vez no... a lo mejor es que la creación de la nación todavía no está completa y que dicha tarea se realiza con adelantos y retrocesos, con logros y actos fallidos. Así la jurisdicción de paz promovida por Bolívar, después de varios intentos y variaciones, finalmente se convierte en ley de la república[...] (Torres, 2002: 97).

En las discusiones previas a los artículos constitucionales también se puede apreciar la misma premisa: 
Aunque la denominación pertenece a una más reciente literatura jurídica, estas autoridades suscitan en América Hispana reminiscencias coloniales. Como lo recuerda un historiador santafereño, la Corona había dispuesto administración "salomónica" de la disputa cotidiana, la de los chicos pleitos de la gleba, que escapan al buen gobierno de 'Cabildo, justicia y Regimiento (Abello Roca, citado por Fajardo, 1991b: 1).

En estricto sentido, los jueces de paz tal como fueron concebidos en 1991 no existieron en el siglo XIX; lo que sí hubo fueron jueces mayores de paz estipulados en los títulos XVI y XVII de la Constitución del Estado de Mariquita, firmada el 3 de marzo de 1815 (cf. Pombo y Guerra 1986 TII: 315-318). Según los objetivos del Estado de Mariquita, estos jueces deberían ser la etapa previa a la utilización de los jueces formales en asuntos civiles, y además deberían ser los presidentes de los cabildos. Junto con lo anterior, los jueces de paz debían ser los encargados de la policía, la inspección de las escuelas, establecimientos de caridad y la junta de sanidad. Tenían autonomía presupuestal y en las comunicaciones oficiales se señalaba claramente que debían ser llamados señorías (Cf. Pombo y Guerra 1986 T II: 317-18). Nada más distinto a los jueces de paz actuales. Este tipo de argumentos es solo una comparación histórica con fines apologéticos.

La única relación de Simón Bolívar con la justicia de paz fue el artículo 112 del proyecto de constitución que presentó a los bolivianos en mayo de 1826 (Cf. Pombo y Guerra 1986 T III: 146). En este caso y en el del Estado de Mariquita, los jueces de paz eran instancias previas de conciliación y su legitimidad estaba dada por dicha funcionalidad.

En el discurso de las organizaciones no gubernamentales también ha sido frecuente el señalar que la justicia de paz servirá para poner de relieve otras concepciones de lo justo. Claramente este paradigma es la versión no estatal de la justicia de paz como política multicultural. Según un funcionario de una de estas instituciones:

La justicia de paz significará por su naturaleza, otra forma de creación del derecho, más abierta, cercana y permeable a las situaciones reales, se empezará a escribir otro derecho en nuestro país, ya no en códigos y leyes, sino en decisiones que consultan los criterios de equidad que como comunidades construyamos en medio de nuestra diversidad cultural y política (Sanín, 2000: 147). 
Además de ser entendida como herencia histórica, como política multicultural, la justicia de paz ha sido concebida como un escenario para que los individuos asuman en parte las responsabilidades institucionales. Según este argumento:

[...] sólo es posible construir una ciudadanía activa delegando en la gente más responsabilidades y capacidad de autorregulación, que se involucre en una administración de justicia descentralizada y participativa que exige de los sujetos tanto como de las instituciones (Gálvez, 2000: 72).

En el locus discursivo de las organizaciones no gubernamentales, financiadas con dineros de Estados centrales y con el aval del gobierno colombiano, también ha sido frecuente legitimar la justicia de paz en tanto supla las dificultades que para el Estado son difíciles de tramitar, sobre todo en el contexto de las sociedades de "masas". Se trata en consecuencia de un problema de cobertura que se debe solucionar con estrategias cuantitativas. Según un autor de esta postura:

[...] en Colombia en particular, y en general en las sociedades contemporáneas de masas, existen dificultades objetivas para que una cantidad de conflictos sean adecuadamente resueltos por el aparato estatal. Esto me parece prácticamente inevitable, por lo cual ineluctablemente tenderán a desarrollarse en las sociedades mecanismos de justicia comunitaria, en el sentido más amplio del término, pues serán las propias personas quienes buscarán resolver sus controversias por fuera del Estado. (Uprimny, 2000: 61).

Para finalizar, la legitimidad de la justicia de paz reside en el discurso de las organizaciones no gubernamentales, como posibilidad de catequesis por cuanto la mayoría de los asesinatos suceden en situaciones domésticas, locales, donde el juez de paz, en tanto actor, vecino y demás, puede intervenir. Según el argumento:

[...]la mayor parte de la violencia colombiana no es de contenido político. Sólo uno de cada diez homicidios tiene connotaciones políticas o está ligado al conflicto armado colombiano. Y muy pocos tienen que ver directamente con el narcotráfico. Esto significa que muchas veces, por conflictos cotidianos que podrían se resueltos de manera pacífica, los colombianos nos estamos matando (Uprimny, 1999: 54). 
En 1991, uno de los ponentes del proyecto constitucional señalaba que la justicia de paz debía ser construida con varias herramientas conceptuales traídas de diversas fuentes:

De la lectura cuidadosa de los escasos materiales que hemos tenido a nuestra disposición, hemos llegado a la conclusión de que es necesario construir con los elementos conceptuales extraídos de las diversas propuestas, una teoría para Colombia sobre los jueces de paz (Fajardo, 1991b: 1).

La verdad es que esta pluralidad conceptual ha sido la responsable de ese gran oxymoron que es la justicia de paz, ya que ésta no puede ser tantas cosas a la vez. Por ejemplo, si es una estrategia de apoyo al Estado no puede ser política multicultural, si es política multicultural no tiene que estar atada al proyecto político de la construcción de la nación, y si hace parte de las estrategias de construcción de la nación no debe basarse en la espuria distinción entre la equidad y el derecho; esto por mencionar sólo las tres contradicciones más evidentes.

\section{La construcción discursiva del juez de paz}

La justicia de paz fue definida como realidad jurídica con la interrelación de los tres ejes enumerados arriba y sus derivaciones; sin embargo, el último axioma fue el más incisivo a la hora de legitimar el proyecto que terminó con la ley de jueces de paz. Es en esta última parte del proceso donde se pasa de hablar del sistema en general para tratar específicamente el tema del operador, el cual fue imaginado de la siguiente manera:

las personas que expropiarán a los dioses una de sus funciones, como lo es la de imprimir justicia, deben presentar unas calidades humanas y morales que acrediten su idoneidad y generen el respeto que requieren para alcanzar sus fines. Además, al tener asegurado su sustento y el de su familia por una actividad distinta a la que realiza como juez, no abusará de ésta tratando de generarse ingresos con ella (Rengifo y Ocampo, 1997: 14).

Sumido en un purismo que nunca ha existido ni existirá, el juez de paz fue concebido como un líder comunal sin problemas económicos, con excelentes cualidades morales y con un carisma propio que le permitiera actuar alrededor de las tensiones de su localidad. Si bien los jueces de paz deberían ser los ángeles para los cuales estaba hecha la ley, la rama judicial aseguró su control al obligarlos a ser capacitados por todas las instancias rituales a las que acuden los jueces formales: 
Su capacitación correrá a cargo del Consejo Superior de la Judicatura, para lo cual contará con el apoyo y experiencia que en este sentido y en materia de mecanismos alternativos de resolución de conflictos, tiene la Dirección General de Prevención y Conciliación del Ministerio de Justicia y del Derecho (Rengifo y Ocampo, 1997: 14).

Lo más importante de la regulación sobre los jueces de paz no es tanto el sometimiento a la normatividad impuesta por el Consejo Superior de la Judicatura, sino la obligación de producir textos legales que deben ser archivados según el modelo del despacho judicial clásico. En palabras de los ponentes de la ley:

[...]consignarán por escrito un breve resumen de lo sucedido en la audiencia de conciliación y si ésta se produce consignarán los términos de la misma y dicha conciliación tendrá fuerza de cosa juzgada, material para exigir su cumplimiento ante el juez competente. Si no se llegara a ninguna conciliación, el juez de paz dejará constancia de ello en el acta, así como la propuesta final de conciliación que haya propuesto a las partes y las demás observaciones que crea conveniente. Esta audiencia reemplaza las audiencias de conciliación en los casos de Ley (Citado por Fajardo, 1991a: 1).

De esta manera lo que inicialmente era autorregulación o multiculturalismo deviene en un formalismo que subsume esta forma de participación política en los vericuetos propios del proceso jurídico clásico.

\section{Discurso y praxis en la justicia de paz}

El análisis discursivo que intento acá cobra sentido si se hacen evidentes las relaciones de los discursos gubernamentales y no gubernamentales con los contextos más amplios de la reforma al Estado y la globalización. Ya hemos avanzado en lo que oficialmente es la justicia de paz (un proyecto de autorregulación, de multiculturalismo, de descongestión de despachos), pero hemos dicho poco en relación con lo que oficialmente no es, esto es, su praxis. Para ello debemos situarnos es un escena etnográfica donde sea posible inscribir el discurso del Estado, de los jueces de paz y de los usuarios. Para ello me referiré al caso específico de una de las grandes ciudades del país, cuyo nombre debemos reservar. 
En el año 2003 la secretaría de Gobierno de la alcaldía de esta ciudad utilizó recursos de un préstamo hecho por el Banco Interamericano de Desarrollo (BID) para la asistencia y fortalecimiento de la jurisdicción de paz. El proyecto, enmarcado en el componente definido por el BID como acceso a la justicia, incluia una evaluación de dicho sistema y una dotación pedagógica y material para los jueces. En efecto, lo primero y lo segundo se llevaron a cabo, y la evaluación de la justicia de paz se realizó apelando a un instrumento diseñado por el Consejo Superior de la Judicatura para medir la relación entre peticiones y trámites. La dotación material consistió en artículos para despacho, y la pedagógica versó sobre los límites entre la justicia de paz y la justicia formal. En síntesis, el dinero invertido se utilizó para formar un grupo de personas que trabajaran como apéndices del sistema jurídico formal, que supieran dónde detenerse en un proceso y cómo remitir casos al Estado.

El éxito de la justicia de paz en este contexto sólo puede ser medido con el criterio de la descongestión de despachos; sólo en ese marco puede aseverarse que la estrategia dió resultados. En la ciudad en mención, los jueces de paz atendieron más casos que cualquier otra entidad gubernamental, produjeron más actas de mérito ejecutivo que cualquier juzgado, centro de conciliación o casa de justicia, y además redujeron a límites insospechados el tiempo en la emisión de documentación oficial para movilizar a la policía u otra entidad.

Como estrategia de autorregulación la justicia de paz en esta ciudad fracasó, aumentaron los índices de violencia en las calles, algunos de los jueces de paz que intentaron mediar en situaciones de violencia fueron amenazados, en casos extremos hubo lesiones personales a familiares de los mismos para evitar su intervención. Como política multicultural ocurrió lo mismo: el exceso de regulación por los consejos seccionales de la judicatura impidió el ejercicio de las autoridades locales, imprimió su sello formal al ubicar a estos operadores en los centros de atención descentralizados de la alcaldía, y en casos extremos dicho control llevó a que fuera más fácil trabajar por la gente, al margen de la justicia de paz.

La justicia de paz, en esta praxis, no se desarrolló como un escenario para evaluar en qué medida era deseable que la ciudadanía asumiera ciertas responsabilidades; tampoco se configuró como un escenario para medir en qué grado el Gobierno era representativo de las localidades o estaba asaltado por los gremios económicos. En todo caso, la discusión sobre el problema de la autorregulación no se dio. En general, varios jueces de paz de la ciudad estuvieron de acuerdo en que la autorregulación y el tema de asumir ciertas responsabilidades sólo es posible en la medida en que las localidades tengan 
garantizados derechos básicos como la educación, la salud, la vivienda y el trabajo. Según un juez de paz de una de las comunas pobres de la ciudad:

De nada sirve que podamos administrar justicia si nada podemos hacer para evitar que los niños aguanten hambre, que no vayan al colegio, que sus papás se queden sin trabajo; ahí es cuando duele la comunidad (Entrevistado en noviembre de 2003).

Lo mismo ocurrió en el caso de la multiculturalidad: varias prácticas vernáculas como el matrimonio y la defensa de la propiedad privada, por sólo mencionar dos, se volvieron problemáticas en el momento en que los jueces de paz fueron visualizados por los funcionarios del Estado. En un caso concreto un juez de paz fue involucrado en un proceso disciplinario por casar una pareja. El argumento oficial señaló que esa no era su competencia, dando como resultado la invalidación del ritual y la pérdida de credibilidad del juez de paz ante su comunidad.

Al dársele un manejo funcional, la justicia de paz se convirtió, en este ejemplo, en un dispositivo que garantiza la marginalidad. La participación democrática que las colectividades pudieran tener se reguló a través de una participación a medias en la rama judicial que impidió un pronunciamiento o participación de estos líderes sobre temas económicos o de redistribución del capital socialmente producido. El reclutamiento de líderes comunales en esta estrategia de participación los hizo visibles frente a macro-poderes que inhiben sus acciones, lo cual facilitó la neutralización de activistas, vía su inmersión en procesos disciplinarios. El saldo a la final favoreció a cualquier tipo de grupos, menos a las comunidades que representan los jueces de paz. Este fenómeno ya había sido señalado por el profesor Santos: en los procesos de comunitarización de la justicia no se abren posibilidades emancipatorias, sino que por el contrario se pasa a controlar, ya no de forma individual, sino colectiva, a las comunidades. En sus palabras:

En mi entender, lo que hay en los actuales programas de informalización y comunitarización de la justicia es que, en tanto hasta ahora las clases oprimidas fueron desorganizadas a nivel individual-como ciudadanos, electores o beneficiarios del Seguro Social-, en el futuro pasarán a serlo a nivel social o comunitario[...] De hecho, la producción comunitaria de servicios, cuando estos implican la resolución de conflictos, el control social, o la reglamentación de actividades colectivas, es un modo no autónomo de producción social. Tiene, cuando más, una autonomía meramente negativa: la libertad de no depender del Estado 
para prestar servicios y desempeñar funciones que el Estado reconoce como legítimas y hasta recomienda. No tiene, en cambio, autonomía positiva: la capacidad de luchar por medidas y servicios que, así sean estructuralmente posibles son funcionalmente incompatibles con los intereses generales[...] (Santos, 1991: 138).

De esta manera la autonomía positiva de las comunidades es cancelada de la agenda, los problemas propios de situaciones de marginalidad son imputados a los individuos, salvando las responsabilidades sociológicamente asociadas a la administración oficial. Algunos de los líderes urbanos, como en efecto sucedió en la ciudad en mención, fueron procesados por su "sospechosa" relación con bandas de delincuentes que en la práctica eran amigos de infancia, familiares o personas que ostentaban otro tipo de parentesco negado por el discurso oficial. De esta manera, lo que en un sentido discursivo era una estrategia de participación de las comunidades, en la praxis se convirtió en un mecanismo de control social que reproduce constantemente la misma exclusión que se supone combate. De tal suerte, los procesos de comunitarización de la justicia vienen a ser, en el extremo de las comunidades, formas refinadas de control, y en el del Estado, las organizaciones no gubernamentales y la banca multilateral, estrategias de mercado tal como lo había anunciado Pierre Bourdieu. En sus palabras:

[...]los esfuerzos por incrementar la demanda, por las vías más diversas, [...] van desde la publicidad, sobre todo en EE.UU., hasta las empresas militantes que tienen por efecto (lo que no quiere decir por fin) abrir los servicios jurídicos a nuevos mercados, promoviendo los derechos de las minorías desfavorecidas o animando a las minorías a hacer valer sus derechos o, más generalmente, intentando conseguir que los poderes públicos contribuyan de manera directa o indirecta a sostener la demanda jurídica (Bourdieu, 2000: 193).

Según lo anterior, debemos dejar en claro que animar a una comunidad a exigir sus derechos no es lo mismo que trabajar para lograr la concreción de esos derechos. En el caso de la justicia de paz, el énfasis en la comunitarización de la justicia como mercado impidió un tránsito coherente entre el discurso y praxis. Lo que ocurrió es que retóricamente se estipularon una serie de situaciones de participación que burocráticamente fueron condenadas. Como corolario, una cita de J. Baudrillard:

El Sur es un productor natural de materias primas. La más reciente es la catástrofe. El norte, por su parte, está especializado en el tratamiento de 
las materias primas, y por lo tanto también en el de la catástrofe. Tutela vampírica, injerencia humanitaria, Médicos sin fronteras, solidaridad internacional, etc. Fase postrera del colonialismo, el Nuevo Orden Mundial. La miseria de los demás se convierte en nuestro territorio de aventuras (Baudrillard, 1993: 105).

De esta manera, estrategias de participación como la justicia de paz deben trascender el foco de atención mercantil de la intervención gubernamental y no gubernamental, y ser también escenarios para que las organizaciones sociales tomen poco a poco el poder estatal que les permita hacer los ajustes necesarios para garantizar derechos básicos. Realizada esta tarea es posible pasar a hablar de autorregulación y de multiculturalidad. Sin este requisito todo lo demás será discurso hegemónico, un safari por la miseria, una caridad bien remunerada.

\section{Referencias}

Andrade, Hernán (1999), "Informe de ponencia", en: Los jueces de paz, Una justicia para el nuevo milenio, Ed. Escuela Ciudadana, Cali.

Ardila, Edgar (2000a), "Elementos para el debate de la figura de los jueces de paz", en: Justicia comunitaria y jueces de paz. Las técnicas de la paciencia, CR. RJCTC. IPC. Bogotá.

. (2000b), "Justicia comunitaria: Claves para su comprensión”, en: Revista de teoría del derecho y análisis jurídico, No. 12, pp .43-52, UN, Bogotá.

. (2002), "Justicia comunitaria y el nuevo mapa de las justicias", en: Criterio Jurídico, Pontificia Universidad Javeriana, Cali.

Baudrillard, Jean, (1993), La ilusión del fin. La huelga de los acontecimientos, Barcelona, Anagrama.

Bourdieu, Pierre (2000), "Elementos para una sociología del Campo jurídico", en: La fuerza del derecho, Ed. Siglo del Hombre, Uniandes e Instituto pensar. Bogotá.

Botelho, Eliane (1993), "Lo alternativo regado en vino y aguardiente", en: El otro derecho, ILSA, Bogotá.

Carvajal, Felipe (compilador) (1999), "Presentación", en: "Jueces de paz. Justicia comunitaria": Transformaciones contemporáneas del derecho, Un instrumento para la convivencia ciudadana, Concejo Municipal de Santiago de Cali.

Corporación Excelencia en la Justicia y Contraloría de la República, (2003), La justicia de paz en Colombia: Del crecimiento a la consolidación, Ed. Corporación Excelencia en la Justicia, Bogotá. 
Corporación Región y Red de Justicia Comunitaria (2000), Justicia comunitaria y jueces de paz. Las técnicas de la paciencia, CR. RJCTC. IPC. Bogotá.

Fajardo, Jaime (1991a), "Creación Constitucional de la figura de los jueces de paz”, Gaceta Constitucional, Número 66 de mayo 3 de 1991.

(1991b), Creación de los jueces de paz y reconocimiento de las jurisdicciones étnicas, Gaceta Constitucional, Número 84 de mayo 28 de 1991. Foucault, Michel (1999), El Orden del Discurso, Tusquets. Barcelona.

Gálvez, Norma (2000), "Institucionalización de las prácticas locales de Justicia en Equidad", en: Revista de teoría del derecho y análisis jurídico, No. 12, pp. 69-84, UN, Bogotá.

Gordillo, Carmen y Rosa Arias (2000), Sistematización evaluativa sobre la jurisdicción de paz en Colombia, Ministerio de Justicia y del Derecho, Bogotá.

Nietzsche, Friedrich W. (1993), Así habló Zaratrusta, Editorial Panamericana, Bogotá.

Pombo, Manuel y José Guerra (1986), Constituciones de Colombia, T. I-IV. Biblioteca Banco Popular, Bogotá.

Rengifo Almabeatriz y José Ocampo (1997), "Informe Ponencia proyecto de ley sobre los jueces de paz”, en: Gaceta del congreso, 346, 28 de agosto de 1997.

Santos, Boaventura (1991), Estado, derecho y luchas sociales, ILSA, Bogotá.

Sanín, T. (2000), "Los jueces de paz en Colombia", en: Justicia comunitaria y jueces de paz. Las técnicas de la paciencia, Ed. Corporación Región, Medellín, R.J.C.T.C. Bogotá.

Torres, César (2000), "Los jueces de paz. Una justicia para pobres o los pobres en lo público", en: Justicia comunitaria y jueces de paz. Las técnicas de la paciencia, Ed. Corporación Región, Medellín, R.J.C.T.C. Bogotá.

Uprimny, Rodrigo (2000), "iSon posibles los jueces de paz y la justicia comunitaria en contextos violentos y antidemocráticos?", en: Revista de teoría del derecho y análisis jurídico, No. 12, pp. 53-67, UN, Bogotá, 2000. 
